\title{
Prognostic Analysis of Patients with Primary Extranodal Lymphoma: A Retrospective Study
}

This article was published in the following Dove Press journal:

Cancer Management and Research

\section{Hanying Shen' \\ Lingling Jiang' \\ Linlin Nie' \\ Xiaohui Fan' \\ Yanqiu $\mathrm{Xu}$ \\ Lingling Yin $^{2}$ \\ Linyan $X u^{1,3}$ \\ Jieyun $\mathrm{Xia}^{2}$ \\ Zhenyu $\mathrm{Li}^{\mathrm{I}-3}$ \\ Feng Zhu (D) ${ }^{1-3}$ \\ Kailin Xu (1D) ${ }^{1-3}$}

'Blood Disease Institute, Xuzhou Medical University, Xuzhou, Jiangsu, 221000, People's Republic of China; ${ }^{2}$ Department of Hematology, The Affiliated Hospital of Xuzhou Medical University, Xuzhou, Jiangsu, 221002, People's Republic of China; ${ }^{3}$ Key Laboratory of Bone Marrow Stem Cell, Xuzhou, Jiangsu, 221000,

People's Republic of China
Correspondence: Feng Zhu; Jieyun Xia Department of Hematology, The Affiliated Hospital of Xuzhou Medical University, 99, West Huaihai Road, Quanshan District, Xuzhou, Jiangsu, 221002, People's Republic of China Tel +8651685806985

Fax +865168580 I527

Email frankfeng_2004@I26.com; jieyunxia03I5@I63.com
Background: Originating from extranodal organs or tissues, primary extranodal lymphoma (PENL) acts in different primary sites with diverse clinical performances and PENL has remarkable geographical differences and lacks the relevant reports in each region.

Patients and Methods: Two hundred and twenty PENL patients were enrolled, and the relevant clinical and laboratory indicators were analyzed. In addition, statistical methods were applied to analyze the effects of different factors on overall survival (OS) and progression-free survival (PFS) of patients.

Results: The three most frequent primary sites of PENL are the digestive system, head and neck, and central nervous system. The patients were classified into groups based on their risk status, resulting in low-risk, medium-low-risk, medium-high-risk, and high-risk, and their respective 3-year OS values were calculated, which showed that 121 patients $(55 \%)$ were in the low-risk group and 3-year OS was $85.2 \%$ (25.9\% medium-low-risk, 3-year OS $66.6 \%$; $15 \%$ medium-high-risk, 3-year OS 61.9\%; 4.09\% high risk, 3-year OS 45.7\%). A multivariate analysis of the Cox regression demonstrated that serum beta 2-microglobulin $\left(\beta_{2}-\mathrm{MG}\right)$ and lactate dehydrogenase (LDH) were independent prognostic factors for OS and PFS, respectively. Both the performance status and pathological subtypes were independent prognostic factors for OS and PFS.

Conclusion: The correlated independent risk factors such as $\beta_{2}-\mathrm{MG}, \mathrm{LDH}$, performance status, and pathological subtypes, were helpful for effectively determining the prognosis of PENL patients and guiding treatment.

Keywords: beta 2-microglobulin, lactate dehydrogenase, performance status, pathological subtype, primary extranodal lymphoma, prognostic analysis

\section{Introduction}

Primary extranodal lymphoma (PENL) originates from extranodal organs or tissues that have narrow and broad definitions. The former refers to lymphomas that occur in organs or tissues without lymphocytes, except in the spleen, thymus, tonsils, and intestinal collections/isolated lymph nodes. The latter refers to lymphomas originating from organs and tissues outside the lymph nodes. ${ }^{1}$ However, there is still a debate about whether lymphomas that originate in the tonsils and Waldeyer's rings should be classified as intranodal or extranodal lymphomas. PENL acts on different primary sites with diverse clinical performances, and typically, the first symptom is less likely to be swollen lymph nodes, nor is PENL accompanied by common B symptoms. ${ }^{2}$ Therefore, most patients with PENL are difficult to diagnose and early misdiagnosis and missed diagnosis rates are high. Numerous articles have shown that there are regional and geographical differences in the incidence of 
PENL. ${ }^{2}$ However, most reports only studied the treatment and prognosis of extranodal lymphoma at a particular site, lacking a systematic study. Additionally, PENL has remarkable geographical differences and lacks a relevant literature summary in each region.

Therefore, the purpose of this study was to summarize the clinical characteristics and efficacy of PENL patients who were initially treated in the department of hematology in our hospital, as well as analyze the incidence of different pathological subtypes and the proportion of different pathogenesis. In addition, through laboratory examination, international prognostic index (IPI) stratification, and other different prognostic factors, we could analyze overall survival (OS) and progression-free survival (PFS) of patients in order to guide future clinical work.

\section{Patients and Methods Medical Records}

Two hundred and twenty PENL patients in the Department of Hematology, at the Affiliated Hospital of Xuzhou Medical University from January 2012 through January 2017, were enrolled. The main inclusion criteria were as follows: 1. Patients with PENL diagnosed by pathological biopsy were initially treated in our department. 2. Positron emission tomography (PET)-CT and other relevant examinations confirmed that lymphoma originated from the extranodal sites. 3. Every PENL patient has data related to pathology, relative laboratory and imaging information. 4 . The patients were treated with at least two cycles of regimens. If the patients' tumors originated in the lymph nodes or other lymphatic tissues (including the spleen and thymus), or if patients were not initially treated in our hospital, or if patients had a history of immunodeficiency diseases such as long-term use of immune-suppressants, organ transplants, or AIDS, they were excluded from the study. The diagnosis of diseases included in this study is based on the lymphoma guidelines issued by the National Comprehensive Cancer Network. ${ }^{3,4}$ Written informed consent was obtained from the patients. This research was approved by the Ethics Committee at the affiliated hospital of Xuzhou Medical University and was conducted according to the guidelines put forth in the Declaration of Helsinki.

\section{Clinical Data}

The clinical characteristics included the patients' sex, age, clinical stage, US Eastern Cooperative Oncology Group
(ECOG) score, and pathology subtypes. Laboratory examinations included white blood cell counts, hemoglobin levels, serum lactate dehydrogenase (LDH), serum beta 2-microglobulin $\left(\beta_{2}-\mathrm{MG}\right)$, and erythrocyte sedimentation rate (ESR) before the first treatment. Cranial MRI, CT scan of the chest and abdomen, superficial lymph node color super and PETCT were included in the imaging examinations.

\section{Methods of Research}

All enrolled patients were followed up through electronic medical records, telephone communication, and outpatient clinics. The follow-up period ended in February 2020 (the median follow-up 51 months), and the patient's OS and PFS were evaluated according to the collected data. OS was defined as the period from diagnosis to death, loss of visit, or final follow-up time for any cause. The interval time from the beginning of treatment to the progress or recurrence of the disease was defined as PFS. Statistical methods were applied to analyze the effects of different factors on the OS and PFS of patients.

\section{Clinical Staging}

Following PET-CT, PENL patients in this study were staged according to the criteria for lymphoma at the Lugano meeting, ${ }^{5}$ the majority of which were phased according to the revised Ann Arbor staging criteria at the Cotswolds meeting. ${ }^{6}$ Primary gastrointestinal lymphoma was phased using the Lugano gastrointestinal lymphoma staging system, ${ }^{7}$ while primary skin lymphoma was based on the TNM system designed for fungal disease stages. ${ }^{8}$

\section{Risk Category}

In this study, PENL patients were staged clinically and stratified according to the IPI score with risk categories.

\section{Statistical Analysis}

All data were statistically analyzed using SPSS19.0 software. The Kaplan-Meier survival curve was drawn for single-factor analysis. The log rank method was used to compare the differences between the different survival curves, and the Cox regression model was chosen for the multivariate analysis. A $p$ value $<0.05$ was considered statistically significant.

\section{Results}

\section{Clinical Characteristics}

The median age of the 220 patients was 56 years (14-86 years), of which 122 were men and 98 were women, with 
a ratio of 1.24 to 1 . There were 77 cases (35\%) with primary digestive lymphomas, and three-year OS was $86.7 \%$ (56 [25.5\%] primary head and neck lymphomas, three-year OS $76.0 \% ; 36$ [16.4\%] primary central nervous system lymphomas, three-year OS $54.6 \%$; 11 [5\%] primary skin lymphomas, three-year OS $51.9 \%$; 9 [4.1\%] primary genitourinary lymphomas, three-year OS $83.3 \%$; 31 [14.1\%] rare rite lymphomas, three-year OS $78.7 \%$ ). The specific primary sites and survival rates are shown in Table 1.

As shown in Figure 1 and Table 2, 176 patients had B-cell lymphomas (125 [71\%] had diffuse large B cell lymphomas [DLBCL]; 37 [21\%] had mucosa-associated lymphoid tissue lymphomas; 3 [1.7\%] had follicular lymphomas; 2 [1.1\%] mantle cell lymphomas and 44 patients had T-cell lymphomas, 27 [61\%] had NK/T cell lymphomas).

\section{Risk Category}

Next, all patients were assessed using their IPI scores (each prognostic factor was scored as 1 , the sum of the indicators was the final IPI score; the low-risk group, medium-low-risk group, medium-high-risk group and high-risk group corresponded to $0-1,2,3$, and $4-5$ points, respectively) the different risk categories. In addition, the cases and the threeyear OS values were collected and shown as follows: 121 patients (55\%) were in the low-risk group and 3-year OS was $85.2 \%$ (57 [25.9\%] medium-low-risk, 3-year OS 61.9\%; 33 [15\%] medium-high-risk, 3-year OS 66.6\%; 9 [4.09\%] high risk, 3-year OS 45.7\%) (Table 3).

\section{Single-Factor Prognosis Analysis of OS and PFS}

The IPI score is still considered as the standard prognostic assessment tool for lymphoma, which regards ages older than 60 years, lymphoma in the III or IV stage, increased serum LDH, poor general condition, and more than one
Table I The Distribution of Primary Sites and Survival Statistics of 220 PENL Cases

\begin{tabular}{|l|l|l|l|l|}
\hline & $\begin{array}{l}\text { Primary } \\
\text { Site }\end{array}$ & Cases & $\begin{array}{l}\text { Percentage } \\
\text { (\%) }\end{array}$ & $\begin{array}{l}\text { 3-Year } \\
\text { OS (\%) }\end{array}$ \\
\hline $\begin{array}{l}\text { Digestive } \\
\text { system }\end{array}$ & $\begin{array}{l}\text { Stomach } \\
\text { Small } \\
\text { intestine } \\
\text { Colon }\end{array}$ & $\begin{array}{l}52 \\
15\end{array}$ & $\begin{array}{l}33.64 \\
6.82\end{array}$ & 86.70 \\
\hline Head and neck & 10 & 4.55 & \\
\hline $\begin{array}{l}\text { Central } \\
\text { nervous system }\end{array}$ & & 56 & 25.45 & 76.00 \\
\hline Skin & 36 & 16.33 & 54.60 \\
\hline $\begin{array}{l}\text { Genitourinary } \\
\text { system }\end{array}$ & $\begin{array}{l}11 \\
\text { Testis } \\
\text { Others }\end{array}$ & $\begin{array}{l}6 \\
3\end{array}$ & $\begin{array}{l}5.73 \\
1.36\end{array}$ & 51.90 \\
\hline Rare sites & $\begin{array}{l}\text { Thyroid } \\
\text { Adrenal grand } \\
\text { Others }\end{array}$ & $\begin{array}{l}7 \\
18\end{array}$ & $\begin{array}{l}14.10 \\
3.18\end{array}$ & 7.73 \\
\hline
\end{tabular}

extranodal involvement site as negative prognostic factors. Additionally, the patient's sex, ESR, serum $\beta_{2}-\mathrm{MG}$, and pathological subtypes were also evaluated.

\section{ECOG Score, Serum LDH, $\beta_{2}-$ MG, and Pathological Subtypes}

Patients were graded according to their performance status before the first treatment and divided into groups based on their performance condition scores, with 169 (74.09\%) patients with a better performance condition (score of 0-1) and $57(25.91 \%)$ patients with a poor performance condition (score of 2-4). As shown in Figure 2A and B, which compared the influence of physical conditions on the patient's

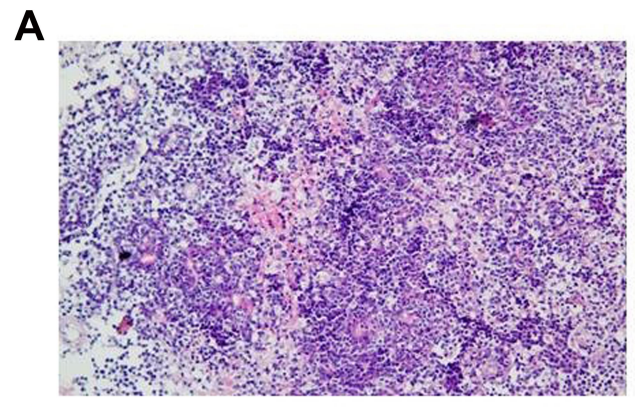

B

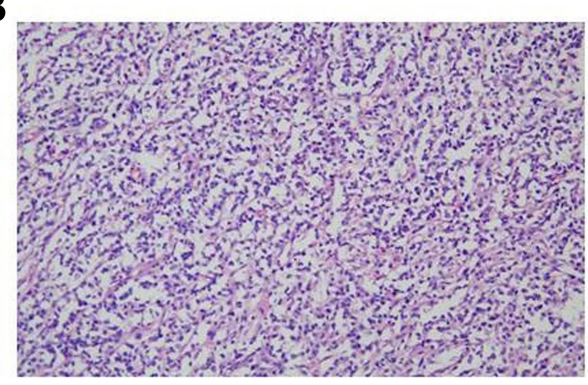

Figure I The pathology of patients with PENL. (A) The pathology of DLBCL (primary site from central nervous system). (B) The pathology of mucosa-associated lymphoid tissue lymphoma (primary site from stomach) magnification $\times 200$. 
Table 2 The Pathological Subtypes of PENL Patients

\begin{tabular}{|l|c|c|c|}
\hline $\begin{array}{l}\text { Cell of } \\
\text { Origin }\end{array}$ & Subtypes & Cases & $\begin{array}{c}\text { Percentage } \\
\text { (\%) }\end{array}$ \\
\hline B-cell origin & $\begin{array}{c}\text { Diffuse large B cell } \\
\text { lymphoma }\end{array}$ & 125 & 56.82 \\
\hline & $\begin{array}{c}\text { Mucosa-associated } \\
\text { lymphoid tissue lymphoma }\end{array}$ & 37 & 16.82 \\
\hline & Follicular lymphoma & 3 & 1.36 \\
\hline & Mantle cell lymphoma & 2 & 0.91 \\
\hline T-cell origin & Others & 9 & 4.09 \\
\hline & NK/T cell lymphoma & 27 & 12.27 \\
\hline
\end{tabular}

Table 3 The Risk Categories of PENL Patients According to IPI Score

\begin{tabular}{|l|c|c|c|c|}
\hline Groups & $\begin{array}{c}\text { IPI } \\
\text { Score }\end{array}$ & Cases & $\begin{array}{c}\text { Percentage } \\
\text { (\%) }\end{array}$ & $\begin{array}{c}\text { 3-Year } \\
\text { OS (\%) }\end{array}$ \\
\hline Low-risk group & $0-1$ & 121 & 55.00 & 85.2 \\
\hline $\begin{array}{l}\text { Medium-low-risk } \\
\text { group }\end{array}$ & 2 & 57 & 25.91 & 61.9 \\
\hline $\begin{array}{l}\text { Medium-high-risk } \\
\text { group }\end{array}$ & 3 & 33 & 15.00 & 66.6 \\
\hline High risk group & $4-5$ & 9 & 4.09 & 45.7 \\
\hline
\end{tabular}

OS and PFS, respectively, the results were statistically significant between the two groups $(\mathrm{P}=0.004, \mathrm{P}=0.006)$.

Serum LDH is an IPI risk score indicator. In this study, the normal levels of serum LDH was not greater than 240U/ $\mathrm{L}$ in all patients, so these levels were further divided into two groups: the normal LDH level group, 152 cases (69.09\%), and the high LDH group (levels exceeding 240U/L), with 68 cases $(30.91 \%)$. Figure $2 \mathrm{C}$ and D show the comparison of OS and PFS of the patients in the two groups, respectively, with the statistical significance $(\mathrm{P}=0.003, \mathrm{P}=0.001)$.

According to the enrolled patient's serum $\beta_{2}-\mathrm{MG}$ levels, the patients were divided into two groups: one group included patients with the serum $\beta_{2}$-MG levels less than or equal to the normal upper limit and the other included those with levels greater than the normal upper limit. A total of $136(61.81 \%)$ patients' $\beta_{2}$-MG levels were in the normal range, and 84 (38.38\%) exceeded the normal limit. As shown in Figure 2E and F, OS and PFS of the patients in the normal $\beta_{2}$-MG level group were higher than those in the group with $\beta_{2}$-MG levels that exceeded the normal group $(\mathrm{P}=0.001, \mathrm{P}=0.004)$.

Given the remarkable subtypes of the pathology and the low number of some pathological subtypes in PENL, the enrolled patients were only divided into two groups according to their cell of origin. There were $176(80 \%)$ patients with B-cell originating lymphomas and $44(20 \%)$ had a T-cell origin. When OS and PFS between the two groups were compared, the results were statistically significant for both OS and PFS values $(\mathrm{P}=0.001,0.002$; see Figure $2 \mathrm{G}$ and $\mathrm{H}$ ).

\section{The Degree of Extranodal Involvement and Gender} Considering that the primary site of the PENL patients was extranodal in the study, the patients were divided into two groups based on their PET-CT examination results before their first treatment was administered. One group had one site of extranodal involvement, accounting for $88.64 \%$ of the cases, and the other group had more than one extranodal involvement site accounting for $11.36 \%$. As shown in Figure $3 \mathrm{~A}$ and B, the comparison of OS between the two groups was statistically significant $(\mathrm{P}=0.021)$, while the comparison of the groups' $\mathrm{PFS}$ was not $(\mathrm{P}=0.266)$.

The patients were divided into two groups according to their sex, where 122 were men (55.45\%) and 98 (44.55\%) were women. Figure 3C and D illustrate that the comparison of OS from the two groups was statistically significant $(\mathrm{P}=0.024)$, while that $\mathrm{PFS}$ was not $(\mathrm{P}=0.065)$.

\section{ESR}

There were 110 patients within normal levels of ESR (not more than $15 \mathrm{~mm} / \mathrm{h}$ ) and 110 patients with levels exceeding $15 \mathrm{~mm} / \mathrm{h}$. Figure 4 confirmed that the comparison of OS of the two groups was not statistically significant $(\mathrm{P}=0.103)$, whereas the comparison of their PFS was statistically significant $(\mathrm{P}=0.032)$.

\section{Age and Clinical Staging}

In this study, there were 131 (59.55\%) patients whose age was greater than 60 years, and $40.45 \%$ were older than 60 years. As shown in Figure 5A and B, there was no statistical significance between the two groups in terms of the groups' OS and PFS $(\mathrm{P}=0.920, \mathrm{P}=0.233)$.

The enrolled patients were divided into stage I-II and III-IV groups according to the above-mentioned staging criteria, with 135 cases $(61.36 \%)$, and 85 (38.64\%) cases in each group respectively. There was no significant differences between the two groups in 

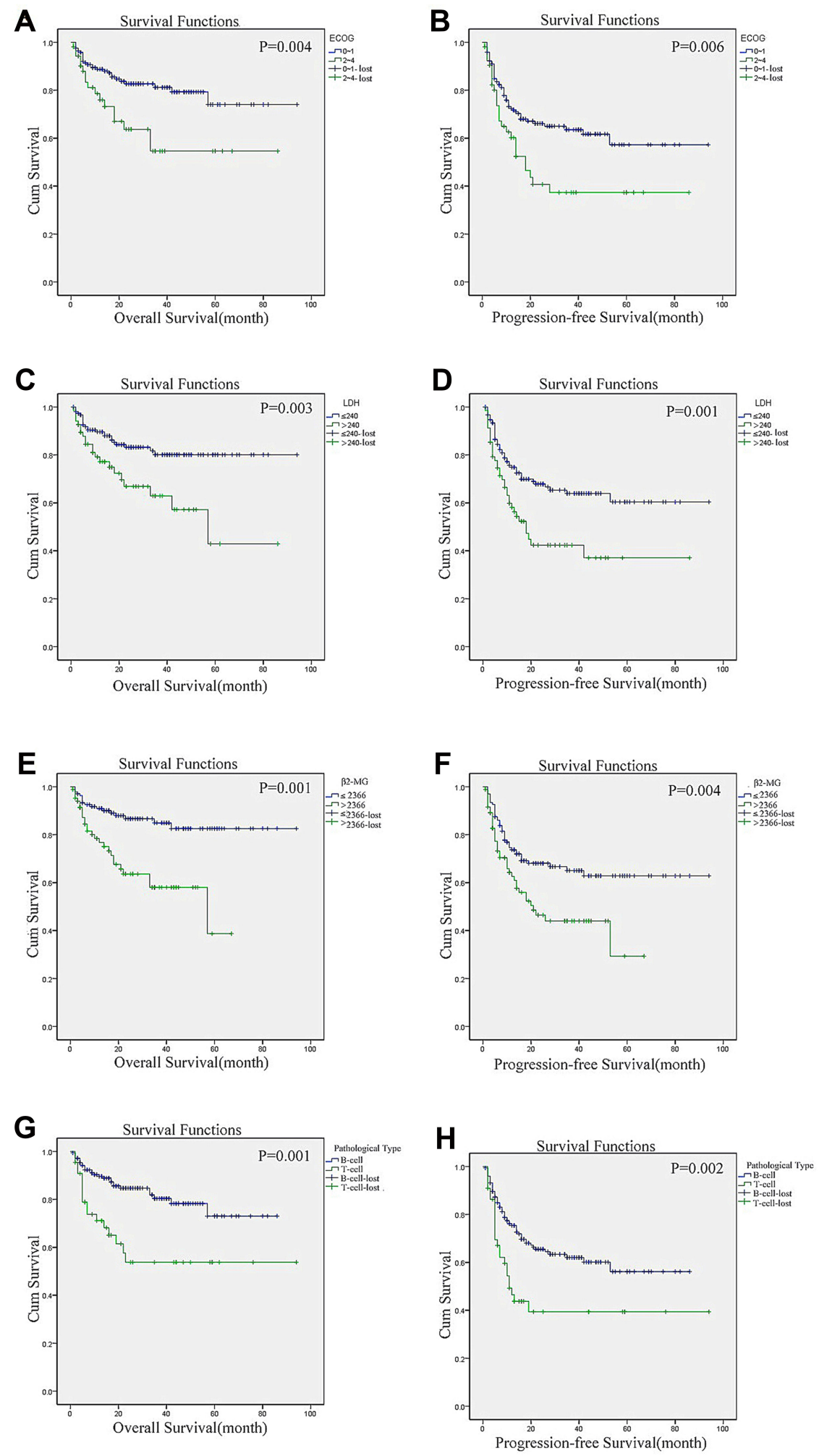

Figure 2 The influences of ECOG scores, serum LDH levels, $\beta_{2}$-MG levels and pathological subtypes on OS and PFS of PENL patients. (A) The influences of ECOG scores on patients' OS. (B) The influences of ECOG scores on patients' PFS. (C) The influences of serum LDH levels on OS of patients. (D) The influences of serum LDH levels on PFS of patients. (E) The influences of serum $\beta_{2}$-MG levels on patients' OS. (F) The influences of $\beta_{2}$-MG levels on patients' PFS. (G) The influences of pathological subtypes on OS of patients. (H) The influences of pathological subtypes on PFS of patients. 
A

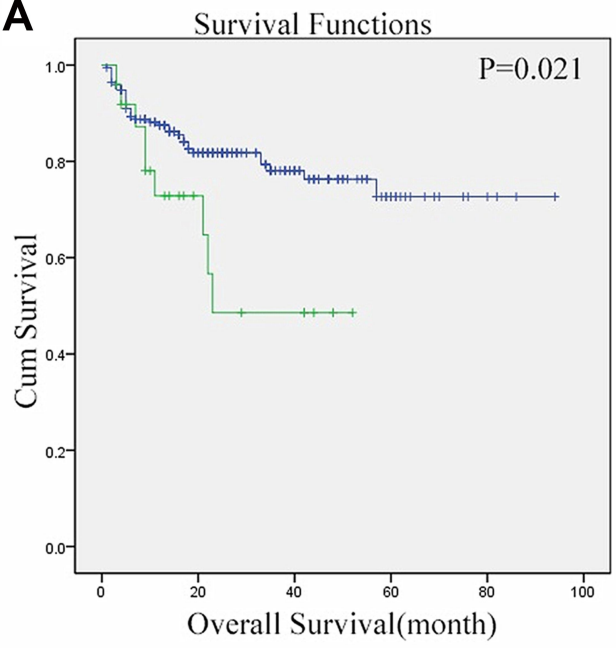

C

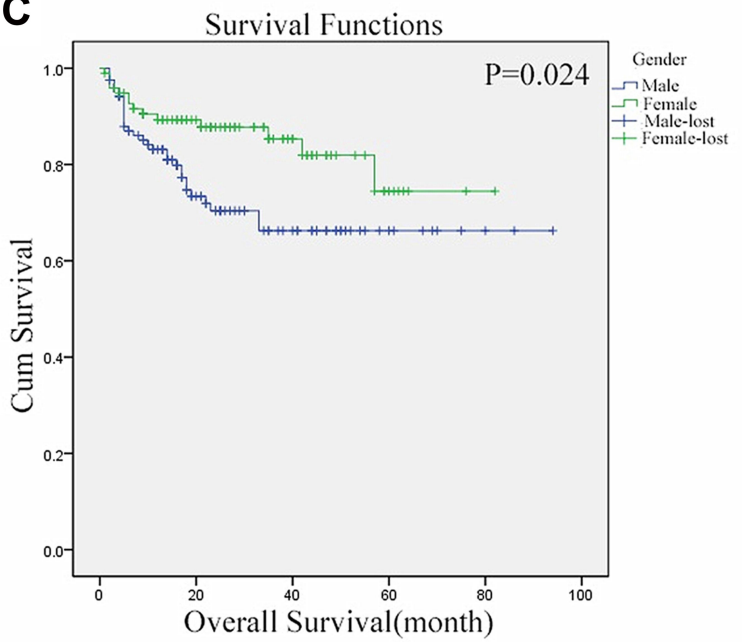

B

B Survival Functions

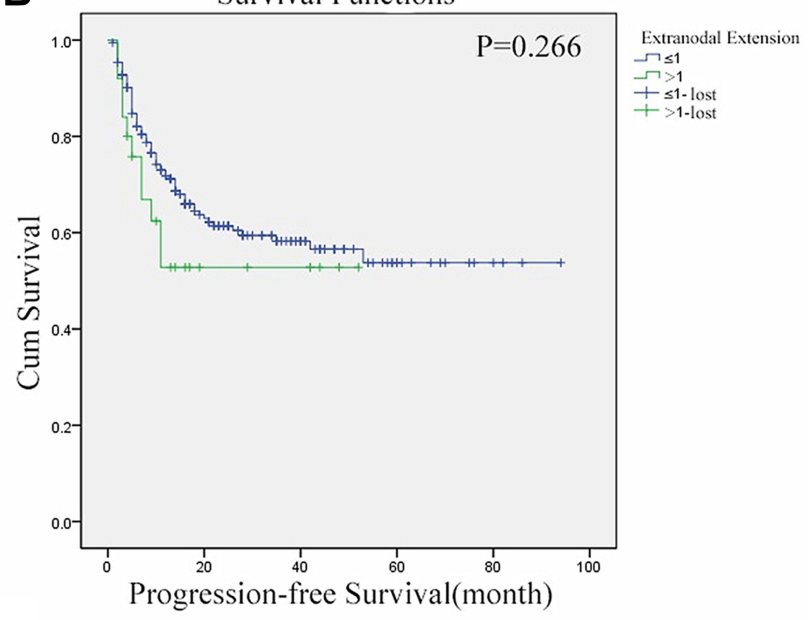

D

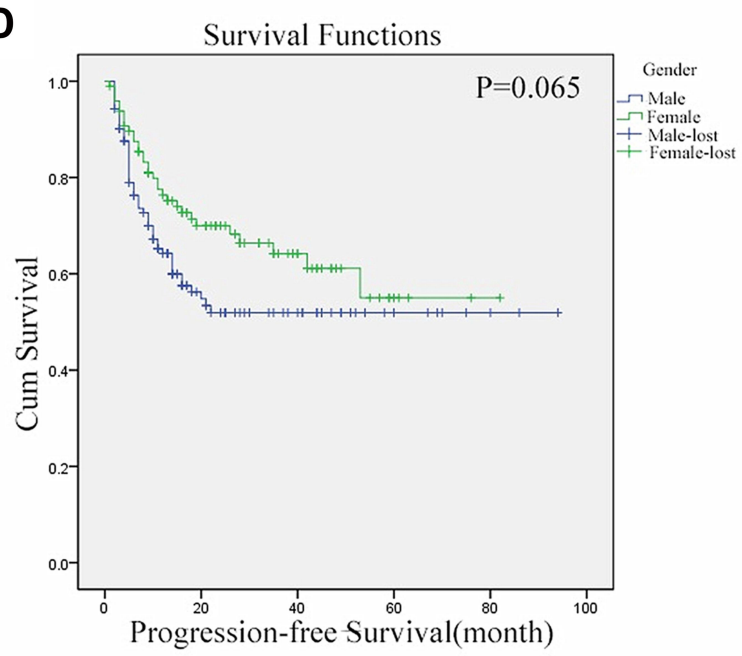

Figure 3 Comparison of the influences of extranodal involvement degree and sex on both patients' OS and PFS. (A) Comparison of the influences of extranodal involvement degree on patients' OS. (B) Comparison of the influences of extranodal involvement degree on patients' PFS. (C) Comparison of the influences of sex on patients' OS. (D) Comparison of the influences of sex on patients' PFS.
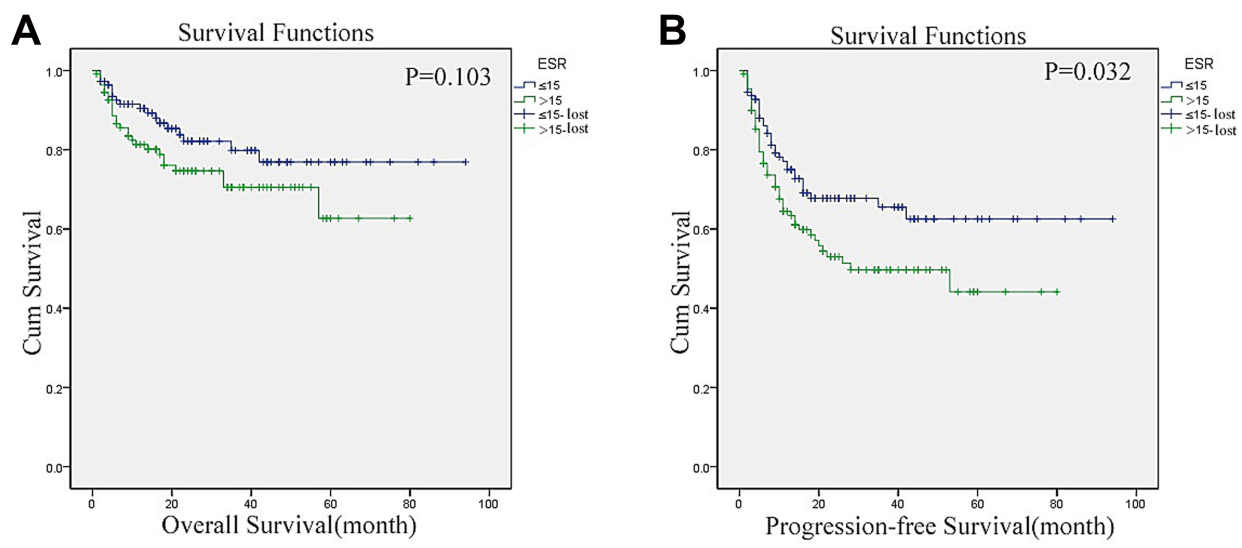

Figure 4 The influences of ESR on OS and PFS of PENL patients. (A) The influences of ESR on patients' OS. (B) The influences of ESR on patients' PFS. 
A
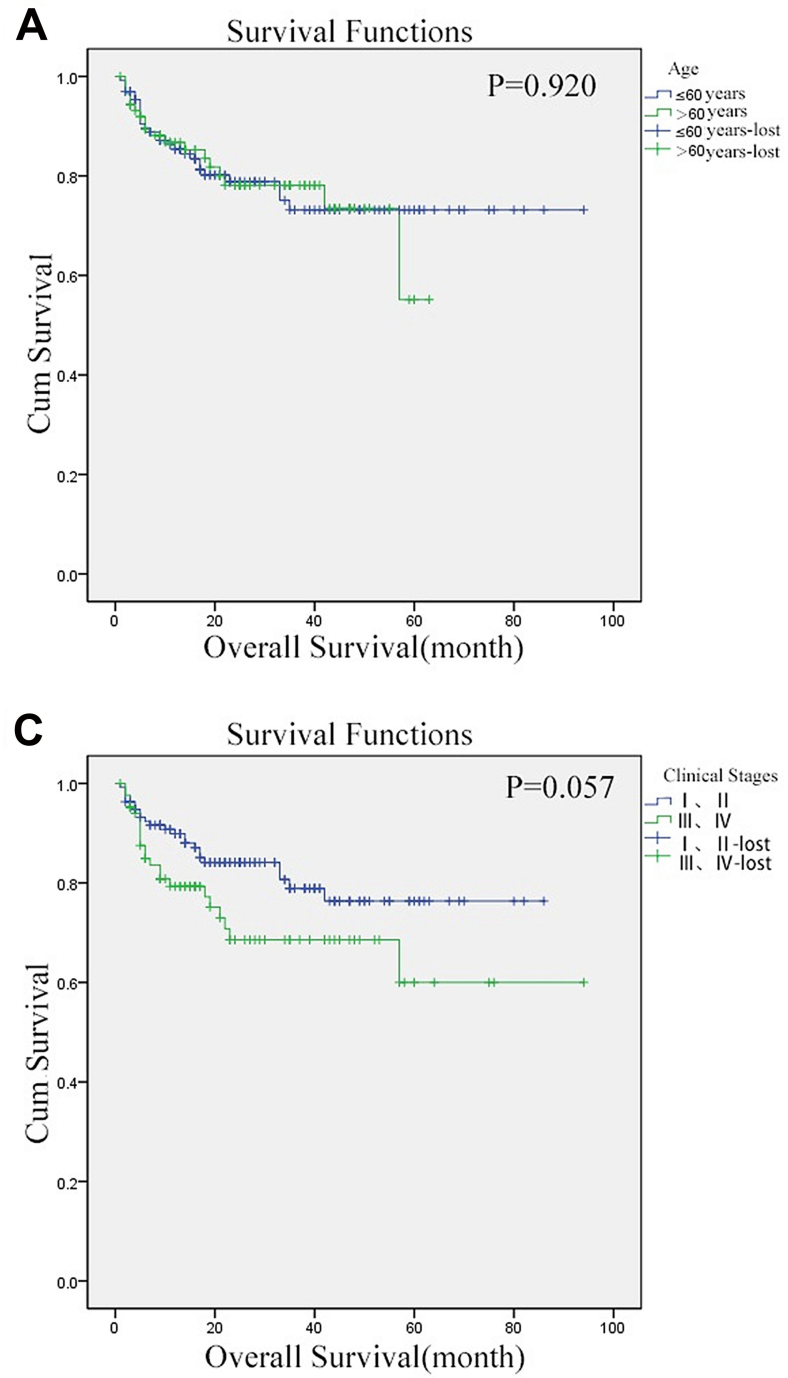
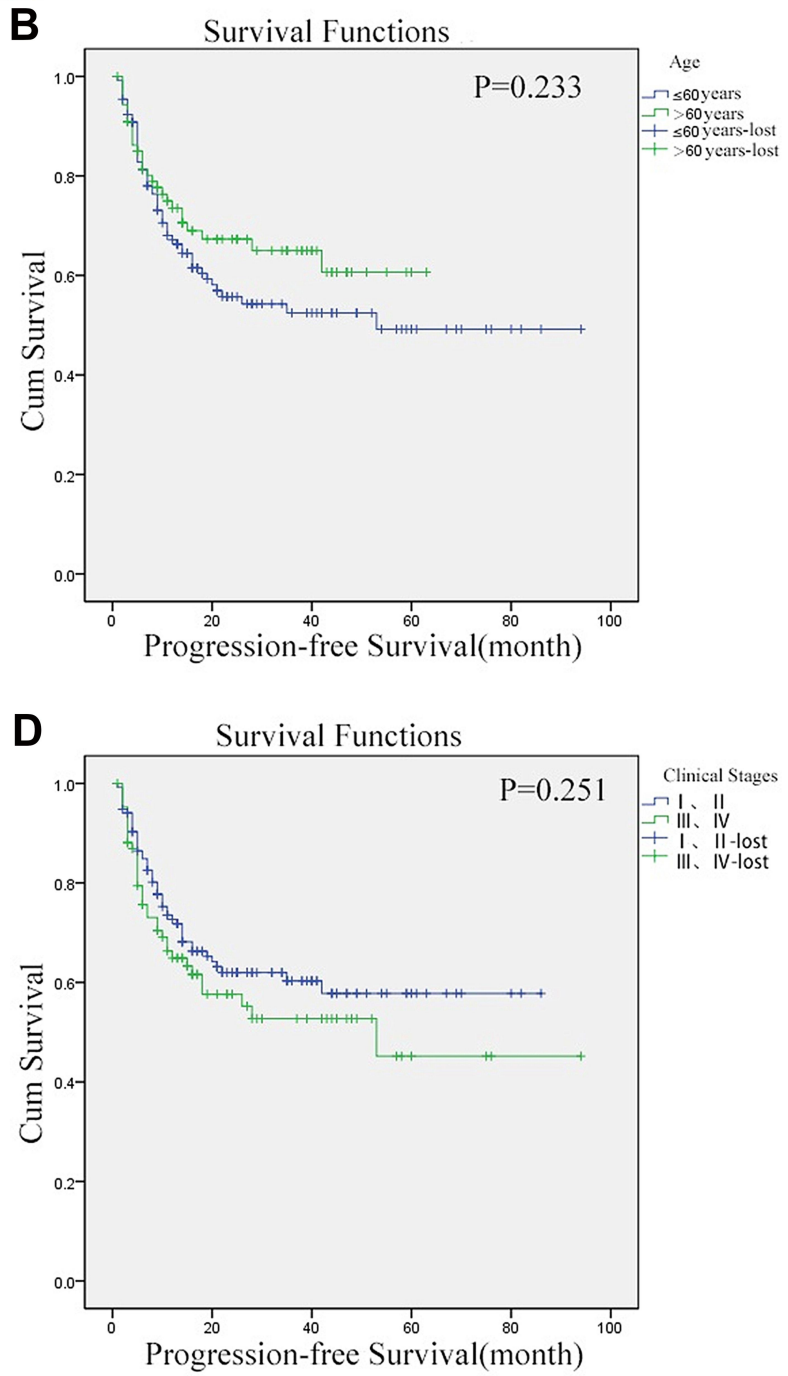

Figure 5 Comparison of age and clinical staging on both patients' OS and PFS. (A) Comparison of age on patients' OS. (B) Comparison of age on patients' PFS. (C) Comparison of clinical staging on patients' OS. (D) Comparison of clinical staging on patients' PFS.

terms of $\mathrm{OS}$ and PFS $(\mathrm{P}=0.057, \mathrm{P}=0.251$, as shown in Figure 5C and D).

The single-factor analysis showed that:

1. Elevated serum LDH, $\beta 2-\mathrm{MG}$, poor performance status, diverse extranodal involvement, male sex, and the pathological subtype of the T-cell origin were all associated with a worse prognosis.

2. Elevated serum LDH, ESR, $\beta 2-\mathrm{MG}$, poor performance status, and pathological subtype of the T-cell origin were the inferior prognostic factors for PFS.
3. Serum LDH, $\beta 2-\mathrm{MG}$, performance status and pathological subtype were all correlated with the patient's OS and PFS.

\section{Cox Regression Model Multivariate Prognostic Analyses}

Based on the multiple factors that affect the prognosis of patients with OS and PFS from the single-factor analysis, the above factors were incorporated into the Cox regression model for a multivariate prognostic analysis (Table 4), the results of which are shown as follows: 
Table 4 The Cox Regression Model Multivariate Prognostic Analysis of PENL Cases

\begin{tabular}{|l|c|c|}
\hline Factors & $\begin{array}{c}\text { OS (P } \\
\text { value) }\end{array}$ & $\begin{array}{c}\text { PFS (P } \\
\text { value) }\end{array}$ \\
\hline Serum LDH level & 0.065 & 0.006 \\
\hline Serum $\beta_{2}$-MG level & 0.007 & 0.221 \\
\hline Performance status & 0.020 & 0.003 \\
\hline $\begin{array}{l}\text { The degree of extranodal } \\
\text { involvement }\end{array}$ & 0.085 & 0.228 \\
\hline Sex & 0.162 & 0.387 \\
\hline Pathological subtype & 0.001 & 0.001 \\
\hline ESR level & 0.857 & 0.570 \\
\hline
\end{tabular}

1. Serum $\beta_{2}-\mathrm{MG}$, performance status, and pathological subtypes were independently related factors for patients' OS.

2. Serum LDH, performance status, and pathological subtypes were independently related factors for patients' PFS.

3. Performance status and pathological subtypes were independently related factors that influenced both the patients' OS and PFS.

\section{Discussion}

As a special type of lymphoma, the concept of PENL has been proposed since the 1960s, whereas the analysis of prognostic factors related to PENL has rarely been reported. In this study, a retrospective analysis was performed on PENL patients. According to our single-factor and Cox regression model analysis, serum LDH was thought to be an independent risk factor that affected patients' PFS. Many studies have confirmed that serum LDH levels is one of the most important indicators of IPI scores, and the higher the level, the worse the prognosis for patients with lymphoma. ${ }^{9,10}$ According to this scoring system, the performance statuses (ECOG scores) of the groups scoring $0-1$ and 2-4 were significantly different from the survival rates, ${ }^{9}$ which was consistent with the conclusion that ECOG scores are independent risk factors for OS and PFS in patients. Studies have shown that elevated levels of serum $\beta_{2}-\mathrm{MG}$ are associated with a high tumor burden, short tumor-cell multiplication time, and inferior prognosis of highly aggressive lymphoma. ${ }^{11,12}$ In addition, serum $\beta_{2}$-MG was considered an adverse prognostic factor for OS and PFS in patients.
However, the mechanism of the relationship between serum $\beta_{2}$-MG and lymphomas is still poorly understood. The pathological subtypes of PENL are mainly DLBCL and mucosaassociated lymphoid tissue lymphomas, and $72 \%$ of extranodal lymphomas were DLBCL, according to a report by $\mathrm{Al}$ Diab. ${ }^{13}$ This study showed that there were $56.81 \%$ of DLBCL cases in the overall PENL cases and $16.81 \%$ were mucosa-associated lymphoid tissue lymphomas, which was consistent with relevant reports. Our multivariate statistical analysis suggested that pathological type was an independent risk factor affecting PENL patients' OS and PFS, and pathological subtypes with a T-cell origin had inferior prognoses. The reasons for this might be as follows: First, CD20 expression is mostly positive in lymphomas of B-cell origin and rituximab has a good effect on CD20-positive B-cell lymphomas. ${ }^{14}$ Second, most lymphomas of T-cell origin are NK/T cell lymphomas and chemotherapy combined with radiotherapy is the main regimen. Several patients have difficulty tolerating tolerate subsequent treatments because of the toxic side effects of radiotherapy, which may affect the prognosis of patients. Third, some lymphomas of B-cell origin are indolent and have a good prognosis, while most lymphomas of T-cell origin are aggressive and have a poor overall prognosis. Intragumtornchai enrolled $181 \mathrm{NHL}$ patients and divided patients with T-cell and B-cell lymphomas into different groups according to their IPI scores. ${ }^{15}$ The results indicated that almost all patients with lymphomas of T-cell origin had a poor prognosis, and a multivariate analysis showed that T-cell origin was the most important independent prognostic risk factor. Although this study was aimed at PENL patients, the overall conclusions were relatively consistent.

The ratio of male patients to female patients was 1.24:1 in this study, and the incidence of PENL in men was slightly higher than that in women, which demonstrated that there was no significant difference in the sex ratio between the PENL patients from our region compared to other regions. The single-factor analysis suggested that male sex was a poor prognostic factor for OS in patients. There were more nasal types of NK/T-cell lymphomas in male patients, and according to pathological type (T-cell origin) as an independent adverse risk factor for patients' OS, the higher proportion of male patients with NK/T-cell lymphomas might reduce OS level. The most common primary site of PENL is thought to be the gastrointestinal tract, but the incidence of lymphoma in the head and neck has increased in some regions; thus, the site of PENL might be related to the region affected. As the main 
primary site, the stomach accounted for $67.53 \%$ of primary digestive lymphomas, which greatly exceeded the proportion concluded by Shannon and colleagues. ${ }^{16}$ Several factors such as the region and food culture, environmental pollution, consumption of a large amount of stimulating food, and other factors might lead to more lesions in the gastrointestinal tract and other parts. In addition, in recent years, the widespread use of gastroscopy and other examinations has reduced the missed diagnosis rate of primary gastric lymphoma. Some patients were examined by gastroscopy only due to gastrointestinal discomfort, and the diagnosis was made via pathology. Furthermore, the primary lymphomas seen in the small intestines were classified as T-cell lymphomas, since colonoscopy and other examinations are difficult to be widely carried out. Thus, when the disease was diagnosed, the patients had intestinal perforation, intestinal obstruction, and other symptoms. Nasal NK/T-cell lymphoma was the main type of head and neck lymphoma seen in our study. Air pollution, oral hygiene, tobacco and the higher infection rate of EBV in China as a developing country contribute to the increased incidence of lymphoma in the nasopharyngeal area.

The patients included in this study had a wide range of ages (4-86 years), however, most of them were middle-aged and elderly; the median age was 56 years, which was similar to the relevant report. ${ }^{17}$ According to IPI scoring criteria, the age of 60 years was regarded as the cutoff level to determine the influence of age on the prognosis of PENL patients. Following the Kaplan-Meier survival curve analysis, we found that the impact of age on PENL patients' OS and PFS was not statistically significant. With the increase in age, DNA mutation probability, adaptive immune dysfunction, epigenetic escape, and other mechanisms will increase the incidence of lymphoma. ${ }^{18,19}$ With the development of the economy, the average life expectancy gradually increases and the average age of lymphoma patients is also gradually increasing, so the reference age of 60 years may be out of date. Roth and other scholars ${ }^{20}$ took age 70 as a dividing standard when studying primary central nervous system lymphoma and found that age was related to the prognosis of patients. Hence, although no correlation between age and the prognosis of PENL patients was found in this study, the prognosis of PENL patients could be studied through different age groups to further clarify the relationship between age and PENL in the future. Our results illustrated that clinical staging factors had a tendency to affect patients' OS, but not their PFS.
We know that PENL has numerous geographical differences in each country or region. Here, this report showed that $\beta_{2}$-MG, LDH, performance status, and pathological subtypes were all the correlated independent risk factors of PENL, which were helpful for effectively judging the prognosis of PENL patients and guiding treatment. Nevertheless, there are also some limitations to this study that should be addressed in future research. First, in order to better collect the data information, some patients with incomplete initial diagnosis and that were treated in other hospitals were excluded, which might have caused a selection bias. Second, the ranges of origin were only from B-cells and T-cells, making it difficult to improve the prognosis analysis between pathological types, so it is necessary to further expand this research to cases of rare lymphomas and to reduce the error caused by the small sample of pathological types. Last, the data were limited by our cohort.

\section{Conclusion}

In summary, serum $\beta_{2}-\mathrm{MG}$ levels, performance status, and pathological subtypes were independent related factors that affected patient's OS prognosis, whereas high serum LDH levels, poor performance status and special pathological subtypes were significantly associated with an inferior PFS; performance status and pathological subtypes were independent factors that influenced OS and PFS in all patients. Feasible and efficacious treatment in light of the relevant risk factors can help improving the prognosis of PENL patients.

\section{Ethnics Statement}

Written informed consent was obtained from the patients. This research was approved by the Ethics Committee at the affiliated hospital of Xuzhou Medical University and was conducted according to the guidelines put forth in the Declaration of Helsinki.

\section{Acknowledgments}

We acknowledge all the patients who were included in the study. Doctor Xuguang Song, Cai Sun, Dongmei Yan, and Wei Sang of the Department of Hematology, the Affiliated Hospital of Xuzhou Medical University were thanked for their guidance and support during the research. This study was supported by the National Natural Science Foundation of China (grant nos. 81600145, 81700199, 81800159 and 81900179); the Natural Science Foundation of Jiangsu Province (grant no. BK20160232); China Postdoctoral Science foundation funded project (grant no. 
2016M590508); the Foundation of Jiangsu Province Six Talents Peak (grant no. 2015-WSW-058); the Foundation of Jiangsu Province Six-one Project (grant no. LGY2018084); and Jiangsu Province Postgraduate Practice Innovation Program (grant no. SJCX19_0936).

\section{Author Contributions}

All authors made a significant contribution to the work reported, whether that is in the conception, study design, execution, acquisition of data, analysis and interpretation, or in all these areas; took part in drafting, revising or critically reviewing the article; gave final approval of the version to be published; have agreed on the journal to which the article has been submitted; and agree to be accountable for all aspects of the work.

\section{Disclosure}

The authors report no conflicts of interest in this work.

\section{References}

1. Krol AD, le Cessie S, Snijder S, et al. Primary extranodal nonHodgkin's lymphoma (NHL): the impact of alternative definitions tested in the Comprehensive Cancer Centre West population-based NHL registry. Ann Oncol. 2003;14:131-139. doi:10.1093/annonc/ mdg004

2. Padhi S, Paul TR, Challa S, et al. Primary extra nodal non Hodgkin lymphoma: a 5 year retrospective analysis. Asian Pac J Cancer Prev. 2012;13:4889-4895. doi:10.7314/APJCP.2012.13.10.4889

3. Zelenetz AD, Gordon LI, Abramson JS, et al. NCCN guidelines insights: b-cell lymphomas, version 3.2019. J Natl Compr Canc Netw. 2019;17:650-661. doi:10.6004/jnccn.2019.0029

4. Horwitz SM, Ansell SM, Ai WZ, et al. NCCN guidelines insights: t-cell lymphomas, version 2.2018. J Natl Compr Canc Netw. 2018; 16:123-135. doi:10.6004/jnccn.2018.0007

5. Cheson BD, Fisher RI, Barrington SF, et al. Recommendations for initial evaluation, staging, and response assessment of Hodgkin and non-Hodgkin lymphoma: the Lugano classification. J Clin Oncol. 2014;32:3059-3068. doi:10.1200/JCO.2013.54.8800

6. Lister TA, Crowther D, Sutcliffe SB, et al. Report of a committee convened to discuss the evaluation and staging of patients with Hodgkin's disease: cotswolds meeting. J Clin Oncol. 1989;7: 1630-1636. doi:10.1200/JCO.1989.7.11.1630

7. Zucca E, Copie-Bergman C, Ricardi U, et al. Gastric marginal zone lymphoma of MALT type: ESMO clinical practice guidelines for diagnosis, treatment and follow-up. Ann Oncol. 2013;24:vi144vi148. doi:10.1093/annonc/mdt343
8. Burg G, Drummer R, Dommann S, et al. Pathology of cutaneous T-cell lymphoma. Hematol Oncol Clin North Am. 1995;9:961-995. doi:10.1016/S0889-8588(18)30053-4

9. Cairo MS, Sposto R, Gerrard M, et al. Advanced stage, increased lactate dehydrogenase, and primary site, but not adolescent age $(\geq 15$ years), are associated with an increased risk of treatment failure in children and adolescents with mature B-cell non-Hodgkin's lymphoma: results of the FAB LMB 96 study. $J$ Clin Oncol. 2012;30:387-393. doi:10.1200/JCO.2010.33.3369

10. Tomita N, Taguri M, Hashimoto C, et al. Evaluation of soluble interleukin-2 receptor and serum lactate dehydrogenase in malignant lymphoma. Ann Hematol. 2015;94:1935-1937. doi:10.1007/s00277015-2448-2

11. Bento L, Díaz-López A, Barranco G, et al. New prognosis score including absolute lymphocyte/monocyte ratio, red blood cell distribution width and beta-2 microglobulin in patients with diffuse large B-cell lymphoma treated with R-CHOP: spanish Lymphoma Group Experience (GELTAMO). Br J Haematol. 2020;188:888-897. doi:10. 1111/bjh.16263

12. Seo S, Hong JY, Yoon S, et al. Prognostic significance of serum beta-2 microglobulin in patients with diffuse large B-cell lymphoma in the rituximab era. Oncotarget. 2016;7:76934-76943. doi:10.18 632/oncotarget. 12734

13. Al Diab AR, Aleem A, Qayum A, et al. Clinico-pathological pattern of extranodal non-Hodgkin's lymphoma in Saudi Arabia. Asian Pac J Cancer Prev. 2011;12:3277-3282.

14. Batchelor TT, Grossman SA, Mikkelsen T, et al. Rituximab monotherapy for patients with recurrent primary CNS lymphoma. Neurology. 2011;76:929-930. doi:10.1212/WNL.0b013e31820f2d94

15. Intragumtornchai $T$, Rotnakkarin $P$, Sutcharitchan $P$, et al. Prognostic significance of the immunophenotype versus the International Prognostic Index in aggressive non-Hodgkin's lymphoma. Clin Lymphoma. 2003;4:52-55. doi:10.3816/CLM.2003.n.014

16. Shannon EM, MacQueen IT, Miller JM, et al. Management of primary gastrointestinal non-hodgkin lymphomas: a population-based survival analysis. J Gastrointest Surg. 2016;20:1141-1149. doi:10.10 07/s11605-016-3129-8

17. Lou LL, Cen XN, Ou JP, et al. [Clinical and pathological analysis of 236 patients with primary extranodal lymphoma]. Zhongguo Shi Yan Xие Ye Xиe Za Zhi. 2014;22:85-92. doi:10.7534/j.issn.1009-2137.20 14.01.018

18. Hartmann K, Illing A, Leithäuser F, Baisantry A, QuintanillaMartinez L, Rudolph KL. Gene dosage reductions of Trf1 and/or Tin2 induce telomere DNA damage and lymphoma formation in aging mice. Leukemia. 2017;31:2853. doi:10.1038/leu.2017.224

19. Sarkozy C, Salles G, Falandry C. The biology of aging and lymphoma: a complex interplay. Curr Oncol Rep. 2015;17:32. doi:10. 1007/s11912-015-0457-x

20. Roth P, Martus P, Kiewe P, et al. Outcome of elderly patients with primary CNS lymphoma in the G-PCNSL-SG-1 trial. Neurology. 2012;79:890-896. doi:10.1212/WNL.0b013e318266fcb2

\section{Publish your work in this journal}

Cancer Management and Research is an international, peer-reviewed open access journal focusing on cancer research and the optimal use of preventative and integrated treatment interventions to achieve improved outcomes, enhanced survival and quality of life for the cancer patient.
The manuscript management system is completely online and includes a very quick and fair peer-review system, which is all easy to use. Visit http://www.dovepress.com/testimonials.php to read real quotes from published authors. 